\title{
Integralidade do cuidado na testagem anti-HIV: o olhar das mulheres
}

\author{
Care integrality in HIV testing: the look of women \\ Atención integral en las pruebas del VIH: la mirada de las mujeres
}

\section{Ana Jaqueline Santiago Carneiro', Edméia de Almeida Cardoso Coelho"}

' Universidade Estadual de Feira de Santana, Departamento de Saúde, Curso de Graduação em Enfermagem. Feira de Santana-BA, Brasil.

"Universidade Federal da Bahia, Escola de Enfermagem, Programa de Pós-Graduação em Enfermagem. Salvador-BA, Brasil.

\author{
Submissão: 22-08-2012 Aprovação: 14-11-2013
}

\section{RESUMO}

A detecção da positividade para o HIV, durante o trabalho de parto, por meio dos testes rápidos, fragiliza as mulheres e gera demandas específicas de cuidados. Este estudo objetivou analisar o cuidado profissional a mulheres com teste rápido positivo para HIV a partir do olhar de mulheres que tomaram conhecimento da positividade durante o trabalho de parto ou puerpério. Trata-se de estudo do tipo exploratório, com abordagem qualitativa. Os dados foram coletados por meio de entrevista semiestruturada e analisados por meio da técnica de análise de discurso. Observou-se que as relações de cuidado às mulheres com teste rápido positivo para HIV se distanciam da integralidade, uma vez que se mantêm distantes e superficiais, sendo norteadas pelo modelo biomédico. A incorporação da perspectiva da integralidade nas ações de saúde exige reflexão por parte do(a)s profissionais, do(a)s gestore(a)s do sistema público de saúde, bem como a capacitação desse(a)s profissionais.

Descritores: HIV; Soropositividade para HIV; Assistência Integral à Saúde; Saúde da Mulher; Trabalho de Parto.

\section{ABSTRACT}

The positive detection during partum labor makes women weak and generates specific care demands. The aim of this research was to analyze professional care to women with positive result from fast HIV test based on the point of view of women who knew the positive result during partum labor or postpartum. This is an exploratory study with a qualitative approach. Data were collected through semi-structured interviews and analyzed using the discourse analysis technique. It was observed that the relations of care for women with positive rapid HIV test are far away from integrality, since they remain distant and superficial, being guided by the biomedical model. The mainstreaming of integrality in health care requires consideration by the professional, public health system managers, as well as training of those professionals.

Key words: HIV; HIV Seropositivity; Integral Health Care; Women's Health; Labor Obstetric.

\section{RESUMEN}

La detección de seropositividad durante el trabajo de parto debilita las mujeres y genera demandas específicas de atención. El estudio objetivó analizar la atención profesional a las mujeres con resultado positivo para el VIH, desde la mirada de las mujeres que se enteraron de la seropositividad durante el trabajo de parto o el puerperio. El estudio es de carácter exploratorio con un abordaje cualitativo. Los datos fueron recolectados a través de entrevistas semi-estructuradas y analizadas con la técnica del análisis del discurso. Fue observado que las relaciones de atención a las mujeres seropositivas para el VIH se distancian de la integralidad, ya que se mantienen alejadas y superficiales, siendo guiado por el modelo biomédico. La incorporación de la perspectiva de la integralidad en las acciones de salud requiere una reflexión por parte de los profesionales, de los administradores del sistema de salud pública, además de la capacitación de estos profesionales.

Palabras clave: VIH; Seropositividad para VIH; Atención Integral de Salud; Salud de la Mujer; Trabajo de Parto 


\section{INTRODUÇÃO}

Os testes rápidos anti-HIV são testes de execução rápida para detecção de anticorpos anti-HIV que fornecem o resultado em até 30 minutos $^{(1)}$. Embora possam ser utilizados com objetivo de diagnóstico em situações especiais( ${ }^{(2)}$, vêm sendo utilizados em maternidades como testes de triagem, possibilitando a implementação rápida de medidas que impeçam a transmissão do vírus da mãe para o(a) filho(a), mesmo durante o trabalho de parto. Esse exame representa importante recurso disponível para essa finalidade, já que existem indicadores da sua alta confiabilidade. Alguns autores ${ }^{(3)}$ encontraram para o teste sensibilidade de $100 \%$, especificidade de $98 \%$, valor preditivo positivo de $75 \%$ e valor preditivo negativo de $100 \%$. Outro estudo ${ }^{(4)}$ encontrou sensibilidade de $100 \%$, especificidade de $99,5 \%$, valor preditivo positivo de $87,5 \%$ e valor preditivo negativo de $100 \%$.

Visando à prevenção da transmissão vertical do HIV, foi criado em 2002, por meio da Portaria no 2104/GM de 2002, o Projeto Nascer, que deveria ser implantado em todas as maternidades do país. Através dele, ficou estabelecido que o teste rápido anti-HIV deveria ser oferecido a todas as mulheres internadas em trabalho de parto que não tivesse realizado testagem para HIV durante o pré-natal ${ }^{(1)}$.

O Ministério da Saúde reconhece que o trabalho de parto não é o momento ideal para a realização do teste anti-HIV. Entretanto, considera que, com a disponibilidade do exame e do tratamento quimioprofilático para a mãe e recém-nascido(a), pode-se reduzir significativamente a chance de infecção da criança. Portanto, negar à mulher e filho(a) essa oportunidade seria muito mais danoso à vida de ambos ${ }^{(1)}$.

Como exame de triagem, o teste rápido necessita ser confirmado posteriormente e deve ser feito com aconselhamento pré e pós-teste, possibilitando, em caso de positividade, instituir, ainda durante o trabalho de parto, a quimioprofilaxia da mãe e do bebê com a zidovudina (AZT) ${ }^{(1)}$.

$\mathrm{Na}$ perspectiva da integralidade do cuidado, para prestar um atendimento que atenda às necessidades das mulheres, é preciso estar disponível para a escuta, o diálogo e a compreensão do contexto social e emocional em que cada uma está inserida. Isso será fator determinante na construção de mecanismos que fortaleçam a mulher para lidar com a experiência da positividade para o HIV.

Porém, observações empíricas mostram que, na prática, as ações profissionais têm sido dirigidas fundamentalmente ao cumprimento dos protocolos que determinam a realização do teste rápido a todas as parturientes que não apresentem sorologia prévia para o HIV. Em muitos casos, a mulher sequer é consultada sobre seu desejo de realizar o teste, ou até o faz sem ser comunicada, pois o sangue para o teste rápido é colhido junto com outros exames de rotina. Ocorre também, em caso de negatividade do exame, que a mulher não é informada sobre seu resultado, prevalecendo a tranquilidade da equipe em saber que estará assistindo uma mulher com sorologia negativa.

Considerando que o cuidado a mulheres com teste rápido positivo para HIV deve se concretizar a partir de necessidades que emergem ao tomar conhecimento do resultado, valorizando-se a multiplicidade de sentimentos presentes e a labilidade emocional que acompanha o processo de enfrentamento do problema, foi realizada uma investigação científica com o objetivo de analisar o cuidado profissional a mulheres com teste rápido positivo para HIV a partir do olhar de mulheres que tomaram conhecimento da positividade durante o trabaIho de parto ou puerpério.

\section{METODOLOGIA}

\section{Caracterização do estudo e enfoque teórico}

O estudo é do tipo exploratório com abordagem qualitativa, sendo utilizado como referencial teórico a integralidade do cuidado. O cuidado na perspectiva da integralidade busca o atendimento ampliado das necessidades de saúde dos sujeitos da atenção, no sentido de superar o modelo hegemônico, centrado nas queixas e nos aspectos biológicos do processo saúde-doença ${ }^{(5)}$.

A integralidade remete à qualificação do cuidado, ou seja, como atributo necessário para lhe conferir excelência, no sentido de representar a perspectiva que melhor possibilita aproximar as práticas profissionais das soluções que as pessoas esperam encontrar para seus problemas de saúde. O cuidado também pode ser utilizado como categoria analítica para se avaliar o modo como são organizadas as ações de saúde ${ }^{(6)}$. Da mesma maneira, a integralidade pode ser utilizada para a avaliação dos serviços e sistemas de saúde ${ }^{(7)}$.

No âmbito da saúde da mulher, a integralidade é considerada $^{(8)}$ como:

A concretização de práticas de atenção que garantam o acesso das mulheres a ações resolutivas, construídas segundo as especificidades do ciclo vital feminino e do contexto em que as necessidades são geradas. Nesse sentido, o cuidado deve ser permeado pelo acolhimento e escuta sensível de suas demandas, valorizando-se a influência das relações de gênero, raça/cor, classe e geração no processo de saúde e de adoecimento das mulheres.

Assim, a integralidade, no âmbito da saúde da mulher, diz respeito à necessidade de considerá-la não apenas como objeto das práticas de saúde, mas como mulher e sujeito que apresenta demandas específicas e diversificadas que necessitam ser atendidas da forma mais ampla possível.

O Programa de Atenção Integral à Saúde da Mulher (PAISM), criado em 1984 como resposta a reivindicações do movimento feminista, é apontado por diversos autores ${ }^{(9-10)}$ como o primeiro programa público a mencionar a questão da integralidade. No entanto, muitas foram as dificuldades para implementação do PAISM. Dentre elas, a forma de organização dos serviços de saúde, a dificuldade de concretização dos princípios do SUS e o despreparo do(a)s profissionais para atender à mulher na perspectiva da integralidade ${ }^{(11)}$.

A Política Nacional de Atenção Integral à Saúde da MuIher, de 2004, amplia a perspectiva do PAISM, mantendo em seus fundamentos a defesa da reorientação das práticas 
profissionais no sentido da atenção integral. Para isso, contempla grupos específicos de mulheres invisibilizadas até então pelas políticas oficiais de saúde, como: negras, lésbicas, indígenas, trabalhadoras rurais, mulheres em situações de prisão, adolescentes, além de destaque para saúde mental, violência doméstica e sexual, doenças crônico-degenerativas e câncer ginecológico, climatério e menopausa, DST e HIV/ AIDS $^{(11)}$.

Essa política considera a integralidade como um dos princípios norteadores e inclui questões relacionadas aos direitos sexuais e reprodutivos, melhoria da atenção obstétrica, do planejamento reprodutivo, atenção ao abortamento inseguro e combate à violência doméstica e sexual. Ao contemplar a saúde como direito de cidadania, abre espaço para práticas mais justas e democráticas para as mulheres.

No que diz respeito à AIDS, uma doença sem cura e que envolve muitos estigmas e preconceitos, para que o cuidado seja orientado pela integralidade, é necessário desenvolver ações que contemplem, além da dimensão biológica, as dimensões social, psicológica, cultural e sexual, na tentativa de atender de maneira eficaz às necessidades das mulheres portadoras ou expostas ao HIV/AIDS, que são complexas. Torna-se, assim, necessária a interação de diferentes saberes profissionais, bem como a articulação entre os vários níveis de assistência, na tentativa de se promover uma atenção eficaz e integral. Todo o cuidado a ser oferecido às mulheres deve ser norteado pelo diálogo e escuta ativa de necessidades com valorização de singularidades. No que se refere à parturiente, diante da necessidade da realização do teste rápido, é preciso uma atitude ética e de respeito que leve em consideração as dificuldades das mulheres em se relacionar com a possibilidade de uma doença temida por toda a sociedade.

\section{Trajetória metodológica}

Constituíram sujeitos do estudo mulheres que haviam realizado teste rápido para HIV durante o trabalho de parto e obtiveram resultado positivo. Foram identificadas no Centro de Testagem e Aconselhamento (CTA), serviço de referência estadual em prevenção para HIV e outras IST, para onde as puérperas são encaminhadas, preferencialmente, após a alta da maternidade, para a conclusão do diagnóstico.

As doze mulheres concordaram em participar da pesquisa e assinaram o Termo de Consentimento Livre e Esclarecido, elaborado segundo a Resolução n 196/96 do Conselho Nacional de Saúde ${ }^{(12)}$, que trata de pesquisas envolvendo seres humanos. O projeto de pesquisa foi aprovado por Comitê de Ética em Pesquisa segundo o Parecer CEP/MCO/UFBA $n^{\circ}$. 97/2006.

Os dados foram coletados no período de julho a setembro de 2006. O material empírico foi produzido por meio da técnica de entrevista semiestruturada. Foi escolhido o puerpério como período para entrevista por considerarmos que no período de internação, as mulheres ainda estão vivendo o impacto do resultado positivo e fragilizadas emocionalmente, contra indicando a realização das entrevistas. Passado algum tempo do período do parto, apresentam melhores condições de avaliar a qualidade do cuidado que lhes foi prestado.
As mulheres foram entrevistadas em período anterior ao da conclusão do diagnóstico, antes do aconselhamento pré-teste inicial. Esse critério foi adotado tendo em vista que, até concluírem todo o fluxograma estabelecido para o diagnóstico definitivo, as usuárias passam por diversas etapas de aconselhamento individual pré e pós-teste, além de um aconseIhamento coletivo. Isso faz com que, ao final desse processo, obtenham maior esclarecimento em relação ao HIV/AIDS. Como o cuidado investigado referia-se àquele que foi prestado na maternidade, ao entrevistarmos mulheres que tiveram seguimento posterior, suas respostas poderiam não retratar exatamente o cuidado que receberam na maternidade.

As entrevistas foram gravadas e transcritas na íntegra, com exceção de duas que não autorizaram o uso do gravador, sendo as respostas registradas manualmente. As entrevistas foram realizadas em consultório, garantindo-se privacidade e sendo utilizados nomes fictícios escolhidos pelas próprias participantes para a sua identificação na pesquisa.

O material empírico foi analisado pela técnica da análise de discurso. O discurso ${ }^{(13)}$ se constitui numa posição social cujas construções ideológicas são materializadas na linguagem, sendo revelada pela análise a visão de mundo dos sujeitos enunciadores. Para operacionalização dessa técnica, foram seguidas as etapas propostas pelo autor: leitura de todo o texto para localizar os elementos concretos e abstratos que conduzem a um mesmo plano de significados; agrupamento dos temas parciais de acordo com os elementos significativos que se somam ou se confirmam formando subcategorias empíricas; formulação de categorias empíricas centrais. Uma delas é apresentada e analisada neste artigo em articulação com a literatura pertinente.

\section{RESULTADOS E DISCUSSÃO}

\section{Modelo técnico de atenção como eixo do cuidado a mu- Iheres com teste rápido positivo para HIV}

A ausência de integralidade no cuidado a mulheres com teste rápido positivo para HIV constituiu o tema de maior abstração extraído do material empírico relativo à pesquisa em foco. No entanto, ao perguntarmos sobre como se sentiram cuidadas pelos(as) profissionais da maternidade, as mulheres apresentaram respostas objetivas que denotam aparente satisfação com os cuidados que receberam:

Me trataram bem, deram o xarope, leite, tudo na hora certa (Cláudia).

Não me senti só. Os medicamentos na hora certa, se eu sentisse alguma dor chamava... (Belinha).

Nos depoimentos, as mulheres expressam satisfação com a presença física constante dos(as) profissionais ou com os cuidados relacionados ao cumprimento de rotinas e procedimentos técnicos pré-estabelecidos. O cuidado para elas está relacionado às experiências do parto e da maternidade, havendo a sobreposição dessas com relação ao risco de uma possível infecção pelo HIV. 
Na perspectiva da integralidade, o cuidado não deve se resumir à dimensão técnica, mas envolve também dedicação e compromisso de um ser para com o outro, no sentido de potencializar subjetividades. Desse modo, "estar presente requer a condição de estar por inteiro no processo. Estar por inteiro implica mais do que estar fisicamente presente. Implica estar com o outro"(14). Assim, torna-se necessária a ausculta das necessidades de cada usuário(a), valorizando sua singularidade.

Na maior parte dos casos, a mulher recebe o resultado do exame em momento de fragilidade emocional, em que está sozinha frente às demandas do trabalho de parto e puerpério, fragilidade potencializada pelas demandas que se somam por ocasião da notícia de positividade para o HIV e pela impossibilidade de compartilhar isso com alguém da sua confiança.

Me botaram numa sala sozinha, lá no canto mesmo da, da... da sala, aí eu tava muito sozinha. Elas não deixavam as pessoas ir conversar comigo... as outras pacientes. É... teve uma menina mesmo que foi conversar comigo, aí eu expliquei pra ela do meu resultado, ela nem... continuou conversando comigo. Aí ela pegou me chamou pra ir no quarto dela ver o filho dela. Aí a enfermeira: Epa, epa, você tá fazendo o que aí? Todo mundo pro seu quarto! Todo mundo pro seu quarto! Assim mesmo. Aí eu peguei e saí do quarto já sabendo porque ela tava falando. Aí eu peguei e saí. Eu ficava muito sozinha (Michele).

O discurso de Michele evidencia que ainda permanece uma visão preconceituosa da doença, inclusive entre os(as) profissionais, levando ao isolamento físico da mulher, à privação do contato com outras pessoas e à conseqüente solidão, o que intensifica o seu sofrimento. Isso revela a representação do(a) portador(a) do HIV como pessoa contaminante e da doença como contagiosa por qualquer contato, utilizando-se de tal representação para justificar a exclusão do convívio social, o que ocorre não somente dentro da maternidade. Além de explicitarem preconceito mantendo a mulher isolada do contato com as demais, os(as) profissionais permitem a incorporação desses significados por parte de outras mulheres porque reproduzem o poder e a voz institucionais, facilmente internalizados como verdade.

Por ser uma doença de transmissão sexual, a AIDS é utilizada para identificar populações transgressoras ou viciosas, o que levou à criação no imaginário social de falsas idéias relacionadas à doença, ao que se pode chamar de metáforas ${ }^{(15)}$. Ainda que se saiba, por exemplo, que a AIDS não é uma doença contagiosa, as pessoas portadoras do vírus são consideradas sujas, poluídas e seu corpo é visto como algo repulsivo. Ainda para essa autora: "as doenças infecciosas associadas à culpa sexual sempre dão origem ao medo do contágio fácil e a fantasias absurdas sobre a transmissão por meios não venéreos em lugares públicos"(15).

Frente à mulher com resultado positivo para HIV, contraditoriamente, apesar do conhecimento científico do qual dispõem, alguns profissionais reproduzem os estigmas criados em relação à doença, levando à culpabilização das pessoas, como aconteceu com Josefa:
Depois que a moça veio e colheu ela foi buscar o resultado, a mesma que me atendeu. Ela perguntou: - Você não tem nada pra me dizer não? Eu disse: - Não, se eu não sabia de nada... Eu disse: - Não. Ela disse: - Tem certeza? Eu disse: - Tenho. Ela falou assim: - Seu teste deu positivo. Aí ela disse: - Você não tem nada mesmo pra me dizer? Eu disse: - Não. Se eu não sabia o que era que ela tava me perguntando... Aí ela falou: - Seu teste deu positivo. Eu disse: - Tá bom. Não posso fazer nada (Josefa).

Esse discurso revela o despreparo profissional para comunicar à mulher o resultado do teste rápido. A profissional parte do princípio de que a mulher já era soropositiva antes do parto, de que já conhecia a sua condição sorológica e de que não queria admitir isso. Ocorre, então, uma transferência de responsabilidade, como se coubesse à mulher comunicar um diagnóstico que ela provavelmente não conhecia. Essa postura constrange a mulher e não considera o seu direito a um adequado aconselhamento pós-teste. Para alguns autores ${ }^{(16)}$, a ideia de responsabilidade, em termos gerais, envolve primordialmente a noção de 'dever' ou 'obrigação' de indivíduos/ instituições prestarem contas a instâncias de regulação - concretas ou simbólicas - por determinadas ações. Assim, os(as) profissionais de saúde, frequentemente, se sentem no direito de regular a vida das pessoas de quem cuidam, assumindo atitudes normativas e paternalistas.

O Ministério da Saúde ${ }^{(17)}$ recomenda que, para a mulher que desconhecia ser portadora de HIV e teve seu diagnóstico realizado através de testagem rápida durante o trabalho de parto, deve haver um aconselhamento pós-teste minucioso, considerando-se a situação pouco favorável do oferecimento do teste durante o trabalho de parto. Além disso, enfatiza a necessidade de se oferecer apoio emocional, criar um ambiente favorável ao diálogo e garantir à mulher o tempo necessário para a assimilação do diagnóstico. Porém, percebemos, através do discurso acima, que essas medidas não fizeram parte da conduta profissional adotada para comunicar o resultado do exame a essa mulher.

Estudo sobre os dilemas morais envolvidos na oferta do teste rápido a gestantes em trabalho de parto verificou ${ }^{(18)}$ que os(as) profissionais revelaram se sentir despreparados(as) para comunicar um resultado positivo, pois o seu discurso não convencia nem a eles(as) próprios(as). Os(as) profissionais vivenciam sentimentos de tensão e ansiedade, pois não sabem exatamente como agir nesse momento. A autora considera também a necessidade de capacitação e apoio psicológico para os(as) profissionais(as), bem como a atenção multiprofissional, na tentativa de facilitar a comunicação do diagnóstico, por exemplo(18).

O despreparo profissional para lidar com o problema é também constatado a seguir:

Os cuidados eles deram. Eu só não gostei de ter dado [o resultado]... Quando eu tava na maternidade, tinha umas pessoas. A menina tava deitada e a outra e a outra do lado e eu. Aí de repente, a moça perguntou se eu sabia do resultado, que eu tava contaminada pelo HIV, há quanto 
tempo. Aí eu fiquei assim, abalada, porque eu não sabia de nada disso. Primeiro me falou isso na presença da menina que tava lá e eu fiquei abalada... Porque se ela chegasse assim, pra mim, né? E me explicasse o resultado na hora que eu perguntei do exame... Mas não. Ela chegou assim, ali na sala mesmo e disse isso. Que eu tava contaminada e se eu sabia há quanto tempo. Assim mesmo (Nega).

A dificuldade de abordar o problema e estabelecer uma relação de diálogo leva a uma atitude antiética e preconceituosa por parte da profissional, tornando a situação ainda mais delicada e de difícil enfrentamento pela mulher, o que se acentua pela falta de aconselhamento anterior, uma vez que pode ser um facilitador de manejo do problema. Esses discursos evidenciam também o descumprimento do princípio da ética profissional.

Alguns autores destacam a dificuldade dos(as) profissionais de atuar nos espaços de cuidado sob a ótica da integralidade, o que decorre do reducionismo que operam sobre os sujeitos e da falta de interpretação de quais são suas necessidades de saúde e de como apoiá-las ${ }^{(19)}$, bem como da dificuldade de mudança das posturas profissionais no sentido de traduzirem o conceito de integralidade em novas práticas ${ }^{(20)}$.

Uma das mulheres entrevistadas evidenciou em seu discurso que alguns profissionais comunicam o resultado adotando critérios que atendem à ética do cuidado, como se vê na seguinte fala:

Ela primeiro perguntou se eu tinha feito o pré-natal e se tinha feito os exames. Eu falei que tinha dado todos negativos. Ela me perguntou se eu tinha feito o de HIV, eu disse que tinha. Ela perguntou aonde, eu falei. Aí ela pediu pra pegar o exame com minha mãe que tava em casa. Aí ela viu e confirmou que tinha dado negativo. Aí ela falou do resultado do HIV. Na hora eu fiquei parada, assim (Michele).

Essa profissional estabelece uma relação que valoriza não somente a possibilidade da transmissão vertical, mas o impacto emocional que a notícia pode trazer para a mulher e seus desdobramentos. Ao contrário das mulheres que trazem o saber do senso comum, os(as) profissionais têm as informações técnicas sobre a infecção, o que Ihes dá responsabilidades frente às as repercussões que esse agravo tem na vida das pessoas.

O trabalho de parto é visto tanto pelas mulheres quanto pelos profissionais como um momento de dor e de fragilidade emocional, não sendo propício para se abordar assuntos como vulnerabilidade ao HIV/AIDS, pois nem sempre a muIher consegue absorver essas informações. Os obstáculos à abordagem profissional sobre a positividade para HIV, no momento do trabalho de parto, ficam expressos no depoimento:

Aí depois que eu tive nenê ele veio e disse que tinha feito um exame lá e que tinha dado HIV, mas que não tinha certeza. Ele tirou o sangue e não explicou, porque na hora eu fiquei muito fraca. Aí depois é que me explicaram. Eu acho que eu não ia entender, porque eu tava muito nervosa, tava com muita dor (Jucilene).
Vê-se nesse depoimento que o trabalho de parto pode criar dificuldades para se estabelecer um diálogo ou para dar informações que possam ser compreendidas pelas mulheres, tendo em vista a possibilidade de desencadear demandas de ordem biológica e emocional. Além disso, a depender do período do trabalho de parto em que a mulher chegue à maternidade, os(as) profissionais precisam definir prioridades na atenção. Fica claro nos discursos dessas mulheres que a experiência do trabalho de parto se sobrepõe a qualquer outro evento que cause impacto sobre a sua saúde. Isso faz com que seja necessário, por parte dos profissionais, permitir um espaço de tempo maior para processar a informação e apreender o significado do exame, como recomendado pelo Ministério da Saúde ${ }^{(17)}$.

A evidente condição de vulnerabilidade das mulheres durante o trabalho de parto reduz a possibilidade de exercerem sua autonomia, já que os(as) profissionais utilizam como justificativa para o não aconselhamento a fragilidade emocional das mulheres nesse momento ${ }^{(18)}$.

Uma vez que têm necessidade de serem atendidas e por não terem a noção da saúde como direito, as mulheres se submetem, sem questionamentos, a qualquer tipo de assistência, inclusive a relações autoritárias ${ }^{(20)}$. Esse tipo de relação gera formas de violência moral ou psicológica, baseadas em mecanismos de dominação, que reproduzem as diferenças de gênero e classe presentes em outras relações sociais, o que deixa as mulheres ainda mais distantes de construir empoderamento.

\section{CONSIDERAÇÕES FINAIS}

$\mathrm{O}$ cuidado às mulheres com teste rápido positivo para o HIV vem se distanciando da integralidade, sustentando-se em um modelo que fragmenta e coisifica pessoas em circunstâncias de vida cujas possibilidades de enfrentamento pelos poderes instituídos encontram-se comprometidas por questões de classe, de gênero e pelas especificidades biopsicossociais do puerpério. $\mathrm{O}$ estudo mostra que um teste rápido positivo para HIV tem repercussões profundas na vida das mulheres, fragilizando-as e produzindo demandas específicas de atenção. No entanto, as mulheres são negadas em sua singularidade e o cuidado se descaracteriza como potencializador de subjetividades.

As relações de cuidado mantêm-se distantes e superficiais, sendo norteadas pelo modelo biomédico, que é reducionista, tecnicista e fragmentário, e em que predominam mecanismos de dominação estruturados pelo saber/poder científico. A mecanização dos profissionais, acentuada pela incorporação crescente de tecnologia e de rotinas institucionais rígidas dificulta a reflexão sobre suas próprias práticas, na construção de um cuidado integral.

A incorporação da perspectiva da integralidade nas ações de saúde exige uma reflexão que deve começar pelos próprios profissionais, que estão na ponta da assistência, a fim de se promover uma apreensão ampliada das necessidades das usuárias dos serviços, como cidadãs que têm direito a uma assistência digna e eficaz. 
Cabe também aos órgãos de gestão e coordenação das políticas públicas promover a capacitação dos(as) profissionais para lidarem com a temática da sexualidade e vulnerabilidade ao HIV/AIDS. Particularmente na enfermagem, em que o cuidado se concretiza como objeto de trabalho, este deve ser ressiginificado de modo a construir possibilidades de abordagem profissional que valorizem as mulheres na sua multidimensionalidade.

\section{REFERÊNCIAS}

1. Ministério da Saúde. Projeto Nascer. Secretaria Executiva, Coordenação Nacional de DST e AIDS. Brasília, DF: Ministério da Saúde; 2003.

2. Ministério da Saúde (Brasil). Portaria $n^{\circ}$. 151, de 14 de julho de 2009. Determina o uso do teste rápido para o diagnóstico da infecção pelo HIV em situações especiais. Diário Oficial da União 16 out 2009;Seção 1.

3. Carvalho RL, Krahe C, Farina G, Paula DO, Richetti N, Crosseti T. Teste rápido para diagnóstico da infecção pelo HIV em parturientes. Rev Bras Ginecol Obstet. 2004;26(4):325-328.

4. Duarte G, Gonçalves CV, Marcolin AC, Paschoini MC, Quintana SM, Mussi-Pinhata MM. Teste rápido para detecção da infecção pelo HIV-1 em gestantes. Rev Bras Ginecol Obstet. 2001;23(2):107-111.

5. Mattos RA. Integralidade e a formulação de políticas específicas de saúde. In: Pinheiro R, Mattos, RA, coordenadores. Construção da integralidade: cotidiano, saberes e práticas em saúde. Rio de Janeiro: IMS-UERJ-ABRASCO; 2003.

6. Camargo Júnior KR. Das necessidades de saúde à demanda socialmente constituída. In: Pinheiro R, Mattos RA, coordenadores. Constituição social da demanda. Rio de Janeiro: ABRASCO; 2005.

7. Hartz ZMA, Contandriopoulos AP. Integralidade da atenção e integração de serviços de saúde: desafios para avaliar a implantação de um "sistema sem muros". Cad Saúde Pública. 2004;20(supl.2):331-336.

8. Coelho EAC, Silva CTO, Oliveira JF, Almeida MS. Integralidade do cuidado à saúde da mulher: limites da prática profissional. Esc Anna Nery Rev Enferm. 2009;13(1):154-60.

9. Costa AM. Programa de Assistência Integral à Saúde da Mulher - PAISM. In: Rede Feminista de Saúde. A presença da mulher no controle social das políticas de saúde. Anais da capacitação de multiplicadoras em controle social das políticas de saúde. Rede Feminista de Saúde. Belo Horizonte: Mazza Edições; 2003. p. 82-101.

10. Luna MEP, Grossemann S, Coelho AR. Princípios do SUS sob a perspectiva de gênero: a integralidade na visão do controle social. In: Coelho EBS, Calvo MCM, Coelho CC, organizadores. Saúde da Mulher: um desafio em construção. Florianópolis: Editora da UFSC; 2006.

11. Ministério da Saúde. Política nacional de atenção integral à saúde da mulher: princípios e diretrizes. Brasília, DF: Ministério da Saúde; 2004.

12. Ministério da Saúde (Brasil). Resolução nº. 196/96. Diretrizes e normas regulamentadoras de pesquisas envolvendo seres humanos [resolução na internet]. Diário Oficial da União 10 out 1996 [acesso em 08 ago 2012]. Disponível em: http://www.bioética.ufrgs.br/res19696.htm\#cinf

13. Fiorin JL. Linguagem e ideologia. 6. ed. São Paulo: Ática; 2003.

14. Silva AL. O cuidado no encontro de quem cuida e de quem é cuidado. In: Lopes MJM, Meyer DE, Waldow VR, coordenadoras. Marcas da diversidade: saberes e fazeres da enfermagem contemporânea. Porto Alegre: Artmed; 1998.

15. Sontag S. Doença como metáfora, AIDS e suas metáforas. São Paulo: Companhia das Letras; 2007.

16. Castiel LD, Guilam MCR, Ferreira MS. Correndo o risco: uma introdução aos riscos em saúde. Rio de Janeiro: Fiocruz; 2010.

17. Ministério da Saúde. Protocolo para a prevenção de transmissão vertical de HIV e sífilis: manual de bolso. Secretaria de Vigilância em Saúde, Programa Nacional de DST e AIDS. Brasília, DF: Ministério da Saúde; 2007.

18. Israel GR. Como é que eu vou dizer pra gestante? Dilemas morais da oferta do teste anti-HIV a gestantes em trabalho de parto: uma contribuição da bioética. Rio de Janeiro. Dissertação [Mestrado em Enfermagem] - Escola Nacional de Saúde Pública, Fundação Oswaldo Cruz; 2002.

19. Mandú ENT. Intersubjetividade na qualificação do cuidado em saúde. Rev Latino-Am Enferm. 2004;12 (4):665-75.

20. Pinheiro R, Guizardi FL. Cuidado e integralidade: por uma genealogia de saberes e práticas no cotidiano. In: Pinheiro R, Mattos RA, coordenadores. Cuidado: as fronteiras da integralidade. Rio de Janeiro: IMS/UERJ/ABRASCO; 2004 